УДК 539

DOI: $18.101 / 2306-2363-2019-2-3-27-34$

\title{
ПОЛУЧЕНИЕ НАНОЧАСТИЦ ОКСИДА МЕДИ (I) ДЛЯ ПРОТИВООБРАСТАЮЩИХ ПОКРЫТИЙ
}

\section{(C) Э. Ч. Хартаева}

Институт физического материаловедения СО РАН

670047, ул. Сахьяновой 6, Улан-Удэ, Россия

Бурятский государственный университет

670000 , ул. Смолина 24а, Улан-Удэ, Россия

E-mail: erzhena.har@mail.ru

\section{(C) А. В. Номоев}

Доктор физико-математических наук заведующий лабораторией физики композитных материалов

Институт физического материаловедения СО РАН

670047 , Сахьяновой 6, Улан-Удэ

Бурятский государственный университет

670000 , Смолина 24а, Улан-Удэ, Россия

E-mail: nomoevav@mail.ru

\section{(C) В. В. Сызранцев}

кандидат физико-математических наук

заместитель директора

Институт физического материаловедения СО РАН

670047 , Сахьяновой 6, Улан-Удэ

E-mail: vveliga@mail.ru

\section{(C) E. В. Батуева}

кандидат физико-математических наук

Институт физического материаловедения СО РАН

670047, Сахьяновой 6, Улан-Удэ

E-mail: elizavlad@mail.ru

Воздействие продуктов обрастания - нароста, образуемого на предметах, находящихся в воде, различными организмами (бактерии, водоросли, моллюски и прочие беспозпозвоночные), минеральными частицами - причиняет разрушительный ущерб днищам судов, нефтяным платформам, конструкционным материалам морских объектов. Одним из распространенных методов защиты металлических изделий от обрастания это нанесение лакокрасочных покрытий с биоцидом, токсичным для микроорганизмов. Из биоцидов наиболее проверенным является оксид меди (I). Наночастицы оксида меди получены методом газофазного синтеза на установке с электронным ускорителем промышленного типа ЭЛВ-6. Преимуществами данного метода перед известными являются высокая производительность и одностадийность процесса получения. Медные нанопорошки исследованы рентгенофазовым методом, просвечивающей электронной микроскопией. Определены оптимальные условия для синтеза нанопорошков оксида меди (I).

Ключевые слова: функциональные материалы, наночастицы оксида меди, биоцидные добавки, микроорганизмы, биокоррозия, лакокрасочные материалы 


\section{Для цитирования}

Хартаева Э. Ч., Номоев А. В., Сызранцев В. В., Батуева Е. В. Получение наночастиц оксида меди (I) для противообрастающих покрытий // Вестник Бурятского государственного университета. Химия. Физика. 2019. Вып. 2-3. С. 35-42.

\section{Experimental Section}

Воздействие продуктов обрастания причиняет разрушительный ущерб днищам судов, нефтяным платформам, конструкционным материалам морских объектов. Обрастание бактериями, водорослями, беспозвоночными животными снижает эксплуатационные характеристики морских судов. Сильное обрастание может вызвать значительное уменьшение скорости судна и увеличить расход топлива до $40 \%$ [1].

В современном мире для профилактики обрастания поверхности морских объектов, погруженных в воду, покрывают специальными красками. В состав противообрастающих красок входят токсичные вещества, выделяющиеся в морскую воду, губительно влияющие на живые организмы. Новейшие противообрастающие краски должны быть экологически чистыми, без содержания ядов в составе. Из всех применяемых биоцидов наиболее проверенным и безопасным является оксид меди (I) $[2,3]$. В 2016 г. комиссия Европейского союза утвердила оксид меди (I) в качестве действующего вещества для использования в биоцидных продуктах типа 21 для покрытий против обрастания [4]. Концентрация токсичного вещества, достаточная для уничтожения микроорганизмов, достигается путем выщелачивания ионов меди в водную среду, вблизи поверхности покрытия. Необходимые концентрации меди на протяжении длительного срока обеспечиваются интенсивностью выщелачивания ионов меди в воду из противообрастающей краски и соответствуют предъявляемым стандартам к покрытиям. Медь, растворенная в морской воде, по своим свойствам наиболее благоприятна для окружающей среды: она лишается своих биоцидных свойств за короткий промежуток времени и вступает в геологический круговорот природы.

Медь демонстрирует различные уровни противообрастающей активности при добавлении в материалы в трех своих формах; нано, микро и макро. Наноформа меди демонстрирует лучшие противообрастающие реакции для общей характеристики биообрастания [5].

\section{Методика эксперимента}

Наночастицы оксида меди были получены методом газофазного синтеза на установке с электронным ускорителем типа ЭЛВ-6 [6]. Преимуществами данного метода являются высокая производительность и широкий диапазон диспергированных металлов, включая тугоплавкие.

На медную мишень воздействовали электронным пучком с различной силой тока, длительность воздействия так же варьировалась. Синтез нанопорошков проходил в изолированной замкнутой системе с циркулирующим несущим газом - аргоном. В реакторе под электронным пучком осуществлялись интенсивный нагрев и испарение меди. В потоке аргона происходило быстрое охлаждение и конденсация паров меди с образованием наночастиц, которые улавливались на 
Э. Ч. Хартаева, А. В. Номоев, В. В. Сызранцев, Е. В. Батуева. Получение наночастиц оксида меди (I) для противообрастающего покрытия судов

фильтре. Образец 1 получен облучением слитков меди электронным пучком с силой тока 25 мА в течении 15 мин. Нанопорошки образца 2 собраны с фильтра после 25 мин воздействия электронным пучком с силой тока 15 мА (табл.1).

Таблица 1.

Ток и время длительности облучения медных слитков

\begin{tabular}{|c|c|c|}
\hline №, образца & I, мА & t, мин \\
\hline 1 & 25 & 15 \\
\hline 2 & 15 & 15 \\
\hline 3 & 15 & 25 \\
\hline
\end{tabular}

Результаты экспериментов и их анализ

Полученные медные нанопорошки исследованы рентгенофазовым методом (РФА), методом просвечивающей электронной микроскопии (ПЭМ).

На дифрактограммах обоих образцов (рис. 1, 2) наблюдаются пики, соответствующие оксиду меди (I) и меди. Интенсивность пиков $\mathrm{Cu}_{2} \mathrm{O}$ намного выше у образца 3 (рис. 2), а рефлексы Сu интенсивнее у первого образца (рис. 1). Результаты количественного анализа приведены в табл. 2. Выявлено, что при изменении параметров пучка и длительности облучения соотношение фаз $\mathrm{Cu}$ и $\mathrm{Cu}_{2} \mathrm{O}$ в полученных нанопорошках изменяется. Результаты исследований полученных нанопорошков рентгенофазовым методом (табл. 2) при воздействии электронным пучком с силой тока 15 мА в течении 15 мин на медный слиток показали следующий результат: $\mathrm{Cu}-84,6 \%, \mathrm{Cu}_{2} \mathrm{O}-11,6 \% \mathrm{CuO}-3,8 \%$.

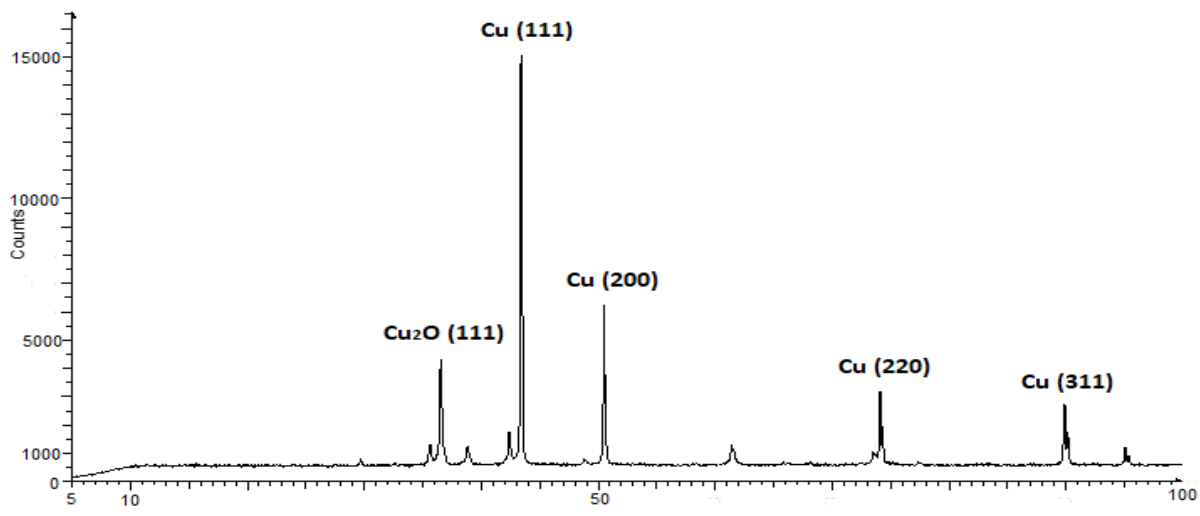

Рис. 1. Дифрактограмма нанопорошков меди. Образец 1. 


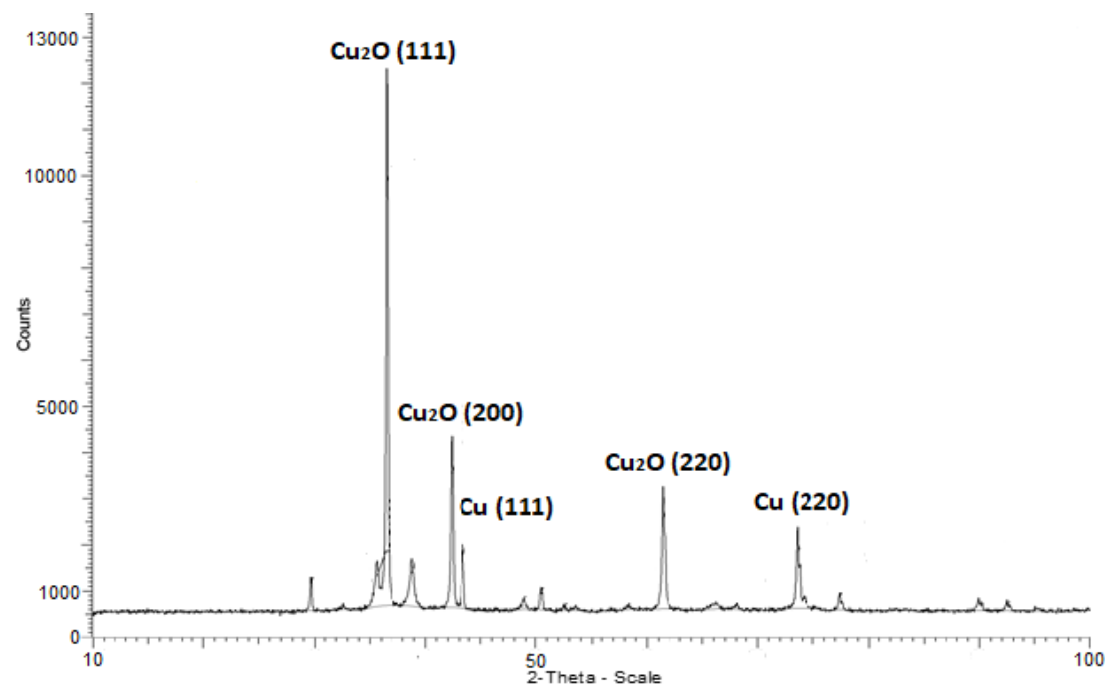

Рис. 2 Дифрактограмма нанопорошка меди. Образец 2.

Увеличение временного интервала до 25 мин воздействия электронным пучком с силой тока 15 мА на медную мишень повышает долю закиси меди до 48 ат.\% от общего состава. И наоборот, повышение сообщаемой энергии в мишень путем увеличения силы тока электронного пучка без изменения времени воздействия снижает долю закиси меди в полученных медных нанопорошках до единиц процентов. Предполагается, что с увеличением длительности облучения мишени происходит уменьшение диаметра металлической сердцевины частицы и увеличение толщины оксидного слоя, образовавшегося за счет окисления поверхности наночастиц в процессе их формирования и хранения в нормальных условиях.

Таблица 2

Результаты РФА нанопорошков меди

\begin{tabular}{|c|c|c|c|c|c|}
\hline No & I, мА & t, мин & $\mathrm{Cu}, \%$ & $\mathrm{Cu}_{2} \mathrm{O}, \%$ & $\mathrm{CuO}, \%$ \\
\hline 1 & 25 & 15 & 98 & 2 & 0 \\
\hline 2 & 15 & 15 & 84 & 11 & 5 \\
\hline 3 & 15 & 25 & 38 & 48 & 14 \\
\hline
\end{tabular}

На микроснимках ПЭМ заметно, что образец 3 имеет форму близкую к сферической (рис. 2a). 
Э. Ч. Хартаева, А. В. Номоев, В. В. Сызранцев, Е. В. Батуева. Получение наночастиц оксида меди (I) для противообрастающего покрытия судов

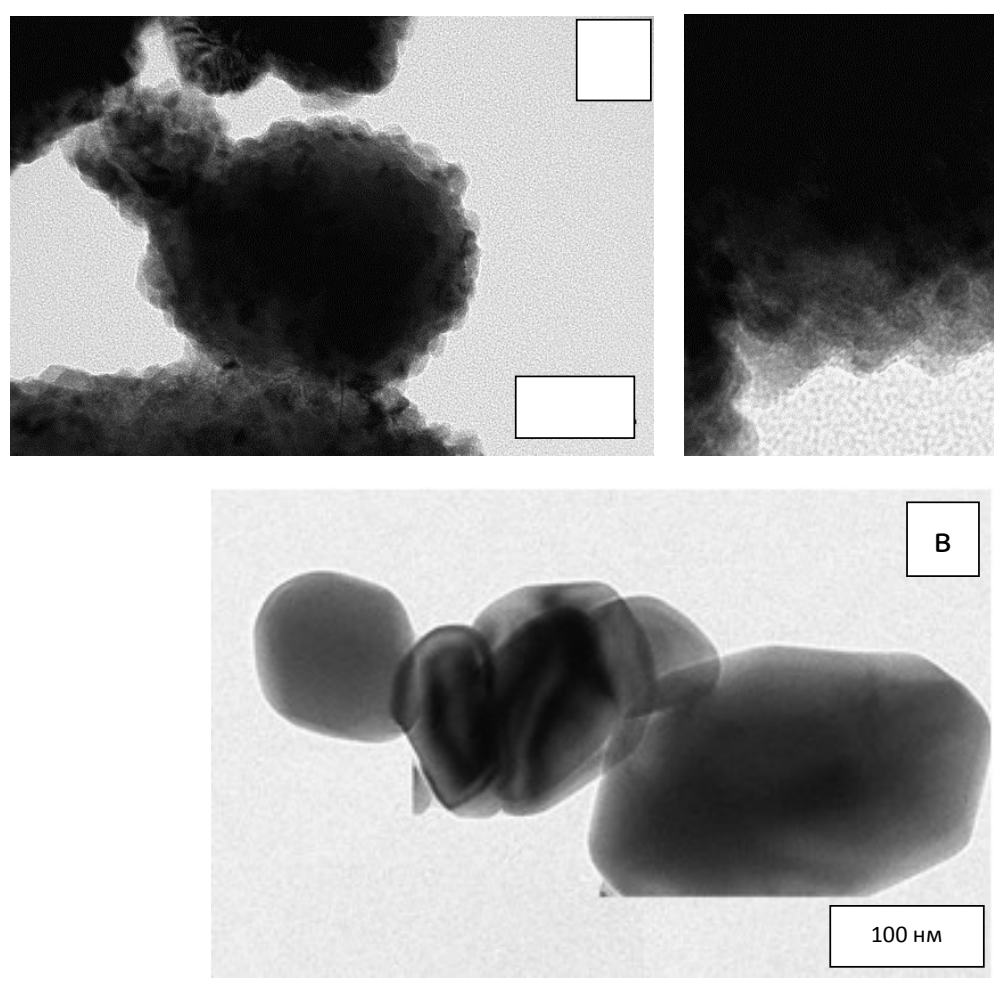

Рис. 2. ПЭМ-изображения медных наночастиц. Образец 3 - а, б; образец 1 - в. Стрелкой указан оксидный слой

Как наблюдается на рис. 2а наночастицы меди образца 3 покрыты плотным оксидным слоем. С увеличением изображения (уменьшением масштаба) рисунка до 20 нм (рис. 2б) на поверхности частицы меди (указано стрелкой) наблюдается рыхлая аморфная структура. На рис. 2в представлено изображение наночастиц образца 1. Частицы имеют четкие контуры, ограненные формы и ровную поверхность и на поверхности отсутствует оксидный слой. Увеличение длительности облучения меди с понижением мощности электронного пучка создают условия - появление неплотностей в контуре - для «загрязнения» кислородом наночастиц в процессе их формирования.

Для синтеза наночастиц закиси меди необходимо, что бы в газовой камере при формировании частиц температура не превышала 2300 К. В этих условиях недостаток кислорода приводит к образованию закиси меди:

$$
4 \mathrm{Cu}+\mathrm{O}_{2}=2 \mathrm{Cu}_{2} \mathrm{O}
$$

Это подтверждается термодинамическим моделированием в программном комплексе TERRA (рис. 3) TERRA - метод моделирования процессов химических превращений в произвольных газофазных системах, основанный на прямом использовании принципа максимальной скорости порождения энтропии. В качестве движущей силы химического процесса принята величина, пропорциональная градиенту термодинамического потенциала [7]. 


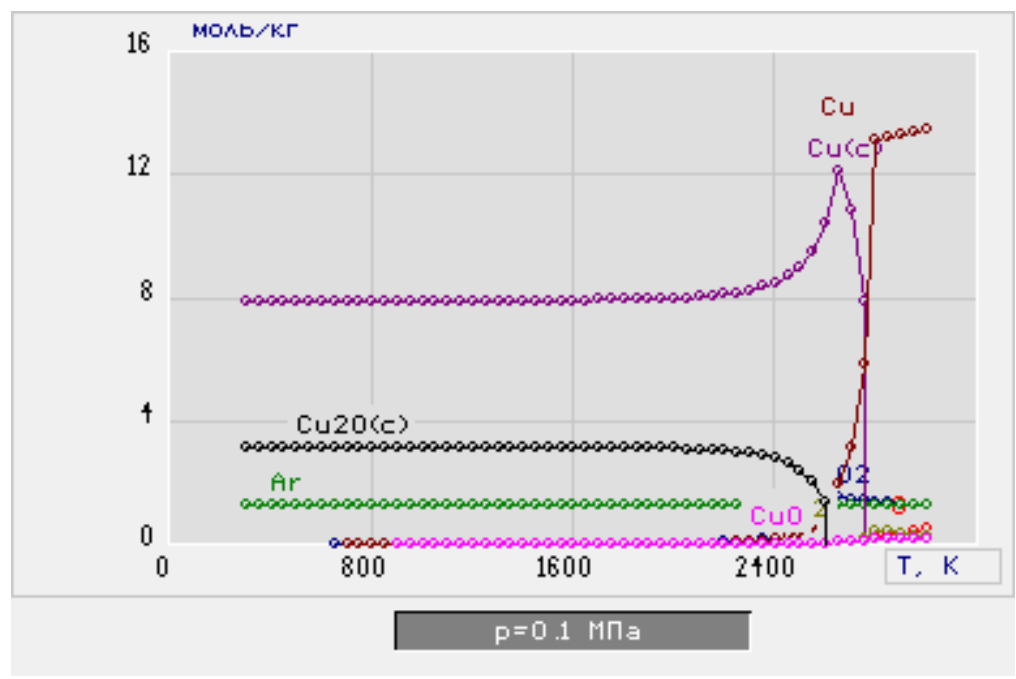

Рис. 3. Термодинамическое моделирование системы $\mathrm{Cu}-\mathrm{O}_{2}$

С помощью программного комплекса Теrra выполнено термодинамическое моделирование системы $\mathrm{Cu}-\mathrm{O}_{2}-\mathrm{Ar}$ в диапазоне от температур 400-2800 К и давлении $\mathrm{P}=0,1$ ППа. Исходный состав компонентов следующий $\mathrm{Cu}-95$ ат.\% $\mathrm{O}_{2}-$ ат. $4 \% \mathrm{Ar}-1$ ат. \%. При нагревании в системе $\mathrm{Cu}-\mathrm{O}_{2}-\mathrm{Ar}$ от $1500 \mathrm{~K}$ до $2600 \mathrm{~K}$ наблюдается образование меди в размере 10 моль/кг и окиси меди в размере 1,5 моль/кг. Повышение температуры свыше 2600 К приводит к разложению закиси меди на медь и кислород. Соединения в виде оксидов меди в таком температурном режиме не образуются.

Таким образом, чтобы получать нанопорошки оксидов меди в больших количествах, необходимо использовать относительно низкие токи пучка электронов и длительное время облучения в установке, работающей по замкнутому циклу.

Определен температурный интервал образования оксида меди (I). Установлено, что образование $\mathrm{Cu}_{2} \mathrm{O}$ происходит в диапазоне температур 1500-2500 К. При повышении температуры наблюдается разложение закиси меди на медь и кислород.

Работа частично выполнена за счет финансовых средств государственного задания (проект № 01201366187).

Материаль публикачии частично подготовлены с использованием оборудования ЦКП «Научные приборы» ФГБОУ ВО «Бурятский государственный университет имени Доржи Банзарова».

\section{Литература}

1. Vietti P. New Hull Coatings Cut Fuel Use, Protect Environment, Fall. — 2009. P. 36-38.

2. https://findpatent.ru/patent/211/2115680.html 

сида меди (I) для противообрастающего покрытия судов

3. Ashraf P. M., Edwin L. Nano copper oxide incorporated polyethylene glycol hydrogel: An efficient antifouling coating for cage fishing net // International Biodeterioration \& Biodegradation. - 2016. - V. 115. - P. 39-48.

4. http://data.europa.eu/eli/reg_impl/2016/1089/oj

5. Chapman J. et.al. Antifouling performances of macro- to micro- to nano-copper materials for the inhibition of biofouling in its early stages // J. Mater. Chem. B. - 2013. - 1 . - P. 6194.

6. Bardakhanov S., Nomoev A., Schreiber M., and oth. Chanel Structures Formed in Copper Ingots upon Melting and Evaporation by a Higt-Power Election Beam // Metals. 2015. - V. 5. - P. 428-438.

7. Трусов Б. Г. Моделирование кинетики химических превращений: термодинамический подход // Вестник МГТУ им. Н. Э. Баумана. Сер. Естественные науки. — 2005. № 3. - С. 26-38.

\section{OBTAINING NANOPARTICLES OF COPPER OXIDE (I) FOR ANTI-FOULING COATING FOR SHIPS}

\section{E. Ch. Khartaeva}

Institute of Physical Materials Science SB RAS

670047, Ulan-Ude, Sakhyanovoy? Str., 6,

Buryat State University

670000, Ulan-Ude, Smolina, Str., 24a

E-mail: erzhena.har@mail.ru

\section{A. V. Nomoev}

Doctor of Physical and Mathematical Sciences

Head of the laboratory of Physics of Composite Materials

Institute of Physical Materials Science SB RAS

670047, Ulan-Ude, Sakhyanovoy, Str., 6

E-mail: nomoevav@mail.ru

\section{V. Syzrantsev}

Candidate of Physical and Mathematical Sciences

Deputy Director

Institute of Physical Materials Science SB RAS

670047, Ulan-Ude, Sakhyanovoy, Str., 6

E-mail: vveliga@mail.ru

\section{E. V. Batueva}

Candidate of Physical and Mathematical Sciences

Institute of physical materials science SB RAS

670047, Ulan-Ude, Sakhyanovoy, Str., 6

E-mail: elizavlad@mail.ru

The presence in the sea water of various microorganisms (bacteria, mollusks, corals, etc.) causes the passage of metal biocorrosion. Due to their build-up and accumulation on the upholstery of the vessels bottoms and other parts, oxygen does not fit well to the surface, various bumps, surface destruction, enhanced corrosion damage in crevices and gaps occur. Marine biocorrosion most often affects steel, alloys based on nickel, aluminum, lead, and tin. The most common method to protect metal products from marine corrosion 
is the application of paints and varnishes. The introduction of copper oxide into the paint leads to its pollution it antifouling. When washed from the coating, Copper oxide, forms an insoluble complex. These substances are toxic to microorganisms. Antifouling paint is applied only to the part of the metal structure that is in direct contact with water.

Keywords: functional materials, nanoparticles of copper oxide, biocidal additives, microorganisms, biocorrosion, paints and varnishes 